\section{A formação de professores em rede no Cirandar}

\author{
Teacher education network through Cirandar
}

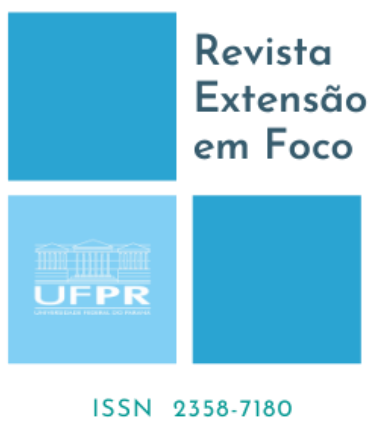

\section{Rafaela Engers Günzel ${ }^{1}$}

Aline Machado Dorneles ${ }^{2}$

\begin{abstract}
RESUMO
Apresenta-se o processo de formação Cirandar: rodas de investigação na escola, um processo anual de formação acadêmico-profissional de professores com aposta na escrita de relatos de experiência e na pesquisa da sala de aula dos professores participantes. Esse processo sustenta-se numa abordagem que argumenta em favor da formação desenvolvida nas relações sociais e interações entre os sujeitos. Em diálogo intenso sobre questões pertinentes aos participantes, problematiza-se a prática docente, exigindo do professor a busca pelos fundamentos que sustentam o seu fazer. Nesse sentido, a sala de aula de cada professor é o objeto de interesse e estudo, de modo que o processo de formação foca na escrita acerca da sua prática educativa, na leitura entre pares, na reescrita a partir da leitura entre pares, na partilha em Roda de Formação como artefatos de pesquisa, formação e constituição de professores-pesquisadores. O Cirandar inspira-se em projetos desenvolvidos em rede com universidades parceiras e nos Encontros Iberoamericanos de Colectivos e redes de Maestros y Maestras que Hacen Investigación e innovación desde su escuela y comunidade, do qual prioriza os processos de autoria dos próprios docentes, a partir do processo de publicização das suas experiências.
\end{abstract}

Palavras-chave: Extensão. Experiência. Escrita.

\title{
ABSTRACT
}

The Cirandar training process is presented: research circles at school, an annual academic professional training process for teachers focusing on writing experience reports and classroom research of the participating teachers. This process is based on an approach that speaks in favor of training developed in social relationships and interactions between subjects. In an intense dialogue on pertinent issues to the participants, the teaching practice is problematized, demanding from the teacher the search for the fundamentals that support their practice. This way, the classroom of each teacher is the object of interest and study, so that the training process focuses on writing about their educational practice, paired reading, rewriting from paired reading, sharing in training circles as research artifacts, training and education of the teacher as researcher. Cirandar is inspired by projects developed in network with partner universities and in the meeting "Encuentros Iberoamericanos de Colectivos e redes de Maestros y Maestras que Hacen Investigación e innovación desde su escuela y comunidade" which prioritizes the process from the teachers themselves, based on the process of publicizing their experiences.

Keywords: Extension. Extension. Writing.

\footnotetext{
${ }^{1}$ Doutoranda em Educação em Ciências pela Universidade Federal do Rio Grande (FURG), Rio Grande, RS, Brasil. E-mail: rafaela.gunzel@gmail.com. Orcid: https://orcid.org/0000-0003-1585-5864

${ }^{2}$ Doutora em Educação em Ciências pela FURG. Professora Adjunta da Escola de Química e Alimentos da FURG, Rio Grande, RS, Brasil. E-mail: lidorneles26@ gmail.com. Orcid: https://orcid.org/0000-00017110-9378
} 


\section{APRESENTAÇÃO}

As palavras determinam nosso pensamento porque não pensamos com pensamentos, mas com palavras, não pensamos a partir de uma suposta genialidade ou inteligência, mas a partir de nossas palavras.

Jorge Larrosa.

No presente texto, descrevemos o processo de formação acadêmico-profissional do projeto Cirandar: rodas de investigação na escola. Inicialmente apresentamos o contexto em que o projeto se insere e a razão da escolha do nome Cirandar. Na sequência descremos experiências consideradas inspiradoras do Cirandar que resultaram em atividades estruturantes do mesmo. Por último, apresentamos a metodologia de trabalho a partir das Rodas de Formação.

\section{A RAZÃO DO NOME “CIRANDAR” E SEU SURGIMENTO}

O início do Cirandar, deu-se, num contexto de intensas discussões sobre a educação e a formação de professores. Para situar esse contexto em que o projeto Cirandar dá seus primeiros passos no ano de 2012, pontuaremos alguns eventos importantes para o surgimento dessa proposta. Em meados de 2010, a Conferência Nacional de Educação (CONAE) configurou-se como um privilegiado espaço democrático e participativo de discussão entre profissionais da educação ${ }^{3}$, que apontara novas perspectivas para melhoria da educação brasileira e a consolidação do Plano Nacional de Educação (PNE). O eixo VI - Valorização dos Profissionais da Educação: Formação, Remuneração, Carreira e Condições de Trabalho, faz referência ao papel e à responsabilidade da universidade no que se relaciona à formação docente. Defende que a educação superior deve ser considerada como principal espaço da formação dos profissionais da educação, incluindo a pesquisa como articuladora do trabalho pedagógico e sua associação com o ensino e a extensão.

Não temos dúvidas quanto a necessidade de apoio coletivo aos esforços e investimentos empreendidos nos processos de formação inicial e continuada. Aqui

\footnotetext{
${ }^{3}$ Compreendemos como profissionais da educação todos os sujeitos envolvidos nas discussões que permeiam a área: estudantes, professores, gestores, representantes de entidades científicas, entre outros.
} 
aproveitamos para apontar que compreendemos o termo "formação continuada" uma denominação recorrente e usual frente ao nome "formação acadêmico-profissional", que melhor representaria a articulação entre escola e universidade, alcançando a extensão e a formação do professor (DINIZ-PEREIRA, 2011).

Ao observarmos as últimas décadas, há um crescente nos investimentos em educação, tanto no que concerne a políticas públicas, legislação, programas institucionais, incentivos de projetos vinculados a órgãos de fomento, como a CAPES e CNPq. Comtemplada por este parâmetro, em 2004, ocorreu a criação da Rede Nacional de Formação Continuada de Professores cujo objetivo foi contribuir para a melhoria da formação de docentes e dos alunos do ensino básico. O ministério da Educação tem o papel de coordenar o desenvolvimento deste programa, implementando por adesão e de forma colaborativa pelos estados e municípios.

A Universidade Federal do Rio Grande (FURG) é uma das instituições de ensino superior que aderiu a Rede Nacional de Formação Continuada de Professores, atuando em projetos junto à Rede de Educação Básica e na produção de materiais de orientação para cursos à distância e semipresenciais. Nesse âmbito, o projeto Cirandar: rodas de investigação na escola foi proposto pela FURG para ser desenvolvido nos municípios de Rio Grande (RS), Santa Vitória do Palmar (RS) e Chuí (RS). A proposta derivou de amplas discussões sobre a formação docente e do reconhecimento de que diferentes perspectivas, sentidos e abordagens precisariam ser considerados, com vistas a um trabalho mais próximo, coletivo, compartilhado e integrado entre a universidade e as escolas de educação básica.

Algumas indagações acerca do motivo pelo qual alguns projetos de formação de professores fracassam mesmo antes de serem implementados circundavam as discussões. Seria a resistência ou descaso dos professores da rede básica de ensino ao que se apresenta como formação? Neste caso, o que seria uma formação considerada pertinente do ponto de vista das necessidades dos professores?

Partimos do pressuposto que a formação acadêmico-profissional dos professores precisa ser realizada com a escola e suas necessidades e ninguém as conhece melhor do que os professores que ali atuam, ainda que possa ser necessário tomar consciência. Nessa perspectiva, seria preciso considerar o contexto escolar com suas características próprias, 
o currículo desenvolvido, as dificuldades laborais, as expectativas, anseios e, principalmente, a disposição interna do professor para a mudança e abertura ao novo.

Com esse pressuposto delineado, o projeto foi nomeado, Cirandar: rodas de investigação desde a escola. Esteve assim designado em suas 9 edições. Em 2021, o Cirandar completa 10 anos de atividades, e ao publicar o primeiro livro de relatos em versão digital, há uma pequena, mas significativa mudança no nome do projeto. $\mathrm{O}$ coletivo que organiza o Cirandar acredita que a linguagem vai constituindo cada sujeito, então, antes havia uma ideia e agora há outra: Cirandar: Rodas de Investigação na Escola. A diferença na escrita está na substituição do "desde" pelo "na". A explicação escrita pela Bruxa Ceamecilda, nos conta que "não é investigação desde a escola, é na escola, entendendo aqui que a universidade é escola. Então o Cirandar é um lugar de skholé, de pensar sobre educação pública: compromisso de todos e todas” (2021, p. 9).

Normalmente, a Universidade toma para si a responsabilidade deste papel de formação que lhe cabe por seu caráter eminentemente pedagógico. Na maior parte das vezes, é protagonista do planejamento de ações formativas desenvolvidas, juntos aos professores, com menor participação dos professores da rede de educação básica na definição de objetivos e da tomada de decisões na formação.

No Cirandar, parte-se do pressuposto que a melhor formação é aquela desenvolvida conjuntamente com os professores da rede de educação básica e com professores universitários, razão pela qual, na estruturação do projeto as discussões consideraram o exposto no documento-referência da CONAE, realizada em 2014. O documento evidencia uma concepção de formação que "considera os profissionais da educação básica como portadores de conhecimentos, experiências, habilidades e possibilidades, os credencia a integrar os programas das universidades e demais instituições formadoras [...]" (BRASIL, p. 89), estes exercendo, portanto, um papel fundamental nos processos formativos.

O projeto Cirandar está embasado também na teoria freireana, tendo em vista que o saber pedagógico está sendo construído coletivamente, num processo de ensinar e aprender compartilhado e dialógico. Assim como no Círculo de Cultura, os participantes do projeto têm sua voz ouvida e respeitada por seus pares: "No círculo de cultura o diálogo deixa de ser uma simples metodologia ou uma técnica de ação grupal e passa a ser a 
própria diretriz de uma experiência didática centrada no suposto de que aprender é aprender a 'dizer a sua palavra'” (BRANDÃO, 2010, p. 69).

Outra aposta do projeto está nas rodas em rede (WARSCHAUER, 2001; SOUZA, 2010; LIMA, 2011) como um modo de realizar processos formativos na escola e em outros espaços, garantindo a liberdade de expressão, o exercício da escuta e o compartilhar de saberes. A ideia é que dancemos, numa grande ciranda, a dança de uma comunidade aprendente que investiga sua própria prática e reflete sobre ela no seu lócus de trabalho - a sala de aula.

O título do projeto Cirandar é prenhe do sentido e do significado impregnado na ação pedagógica deste projeto do ponto de vista do que comumente se interpreta da palavra Ciranda nas cantigas de roda. $\mathrm{O}$ que motivou a escolha do nome, inicialmente teve a intenção de valorizar um repertório musical da raiz da nossa cultura, lembrando especialmente que Villa-Lobos, o maior expoente da música nacionalista brasileira, reconhecido também como um marco na educação musical em nosso país, que se inspirou nas cirandas para compor obras reconhecidas no Brasil e no exterior.

Villa-Lobos foi músico e educador preocupado com a formação de professores, tendo criado em 1932, durante o governo Vargas, o Curso de Pedagogia de Música e Canto Orfeônico, ministrado pelo próprio músico. Muitas das composições de VillaLobos são baseadas em temas folclóricos, sendo que compôs duas coleções para piano solo chamadas Cirandas (16 peças sobre temas populares brasileiros) e Cirandinhas (12 partituras também sobre temas populares brasileiros, mais especificamente de rodas infantis). Com isso, a referência das Cirandas no título, visa intensificar, junto aos participantes do projeto, o sentido de pertencimento a um país, à própria escola e à formação de professores. As ideias fortes de fusão de diferentes linguagens como canto, dança e palavra acionando instâncias racionais e sensíveis também estão nos pressupostos de um processo de formação que agregue a dimensão estética em suas ações.

Na escolha do título do projeto, também nos reportamos à tradição gaúcha que inclui, em seu cotidiano, a roda de chimarrão. Consumido na cuia, passa na roda, de forma fraterna e estimuladora de conversas informais, num compartilhar de afetos e saberes. Com o propósito de desenvolver a formação de professores de forma prazerosa, coletiva, diferenciada, compartilhada no próprio ambiente de trabalho dos professores é que estamos desenvolvendo, desde 2012, o projeto Cirandar: rodas de investigação na 
escola. Contudo, faz-se necessário explicitar a ampliação no sentido da palavra Cirandar, quando assume o caráter de permanecer como formação acadêmico-profissional e como consequência, evoluiu pelo próprio processo. Ou seja, é pertinente destacar que o próprio processo fez com que o projeto Cirandar e suas intencionalidades evoluíssem, assim como sua origem advém de outras iniciativas, conforme sugere (re)pensar o tópico que segue.

\section{EXPERIÊNCIAS INSPIRADORAS}

\section{A concretização em uma longa trajetória}

O Cirandar foi inspirado em experiências anteriores de constituição de redes, especialmente na forma de projetos de formação de professores de Ciências entre as universidades UNIJUÍ, PUCRS e FURG. Essa parceria foi institucionalizada em 1981 pela política pública CAPES/PADCT de formação de 'Redes' quando surgiu a Rede ACOMECIN - Ação Conjunta para a Melhoria do Ensino de Ciências e Matemática no Rio Grande do Sul - em que universidades gaúchas articularam-se em torno de ações conjuntas. Desde então, reforçam-se as Redes por meio de projetos conjuntos, como foi o projeto 'Articulação entre desenvolvimento curricular e formação de professores', a partir de um edital aprovado em 2006.

Neste último, a ideia de Rede se concretizou em interações a partir de produções escritas. Esta Rede partiu do pressuposto de que o desafio da produção escrita que vai se qualificando pela interação dialógica com o outro, envolvendo temas da formação e da docência, é que os participantes podem se envolver em formação acadêmico-profissional, assumindo-se como pesquisadores e produtores de um tipo específico de conhecimento, conhecimento de professor. Assim as autorias se constituem, com crescimento de todos a partir da interação com o outro diferente e com outras vivências e conhecimentos. Essa ideia de Rede foi inspiradora do Cirandar.

O projeto pautado em redes universitárias, com a participação de professores da rede pública de educação básica, teve duração de 4 anos e a cada ano uma das Instituições organizava o encontro interinstitucional. Nesses encontros anuais, os textos previamente discutidos entre pares, eram novamente discutidos. Deste processo, originaram-se dois 
livros com as sínteses de escrita de mais de cem participantes ${ }^{4}$ : Construção curricular em rede na Educação em Ciências (Galiazzi, Auth, Moraes, Mancuso, 2007) e Aprender em Rede na Educação em Ciências (Galiazzi, Auth, Moraes, Mancuso, 2008).

Para compreender a importância do referido projeto na constituição do grupo de pesquisa CEAMECIM - Comunidades Aprendentes de Educação Ambiental e Educação em Ciências - foram extraídos do documento de avaliação produzido por Moraes e Galiazzi (2011) as principais conclusões que serviram de análise do projeto, bem como, estruturam as atividades do Cirandar.

A avaliação produzida pelos participantes, segundo os autores, permitiu afirmar que os diferentes projetos em parceria pelas três instituições universitárias sempre constituíram e constituem continuidades, quando da possibilidade de fomento por órgãos financiadores, nas descontinuidades circunstanciais das interações interinstitucionais. É da mesma análise que se compreendeu que a constituição de coletivos que se proponham a aprender em conjunto constitui processo lento e difícil, com integração de uma diversidade de metas e objetivos. Não se tratou, naquelas experiências, de diminuir as diferenças dos grupos, mas de possibilitar aprendizagens a partir das mesmas. As diferenças de perspectivas teórico-ideológicas é que possibilitaram avanços em várias direções e sentidos.

Sobre a escrita, ponto chave do projeto, foi constatada uma resistência inicial ao se expor pela escrita na rede. Os participantes mostraram movimentos diversos nas diferentes instituições e solicitaram diferentes tipos de mediação, entretanto, de modo geral, ocorreu uma compreensão ampliada do processo da produção escrita coletiva e de sua importância como modo de aprender e como modo de valorizar todos os professores envolvidos como produtores de conhecimento.

Seguindo na análise, reafirmou-se que a escrita, no projeto, foi entendida como modo de aprender em rede, modo de reconstrução de conhecimentos e possibilidade de contribuição na aprendizagem dos outros. Pela escrita, na interação tanto presencial como virtual, se proporcionaram oportunidades singulares de aprendizagem e de formação para todos os envolvidos. Através da mesma, pôde-se afirmar que ocorreu a valorização da leitura, seja dos textos produzidos pelos outros participantes, seja de leituras próprias que

\footnotetext{
${ }^{4} \mathrm{O}$ projeto Articulação entre desenvolvimento curricular e formação de professores foi financiado pela agência de fomento FINEP e teve coordenação na FURG.
} 
fundamentaram as produções. $\mathrm{O}$ envolvimento intenso em leituras e produções escritas esteve muito intimamente relacionado ao exercício da leitura crítica do outro.

A partir do investimento em produções escritas, aperfeiçoadas gradativamente pela crítica entre pares, os participantes foram se assumindo cada vez mais como sujeitos em suas próprias autorias. Em autorias compartilhadas cada um foi se percebendo capaz de elaboração própria, com crescimento da autoconfiança para assumir a própria voz em contextos coletivos. Juntamente com isto, o projeto como um todo se constituiu em espaço de divulgação e publicação das produções. Tendo em vista a diversidade obtida pela heterogeneidade do grupo, critérios de qualificação coletivos foram discutidos e resultaram avanços tanto na prática docente quanto na reflexão sobre a mesma.

Até aqui, procuramos apresentar a constituição do Cirandar a partir de outras iniciativas de articulação entre o desenvolvimento curricular e a formação de professores, a exemplo do que foi o projeto em parceria entre três instituições universitárias com integração entre programas de pós-graduação e as redes de educação básica. A seguir, apresentamos outra iniciativa igualmente pertinente.

\section{Os encontros de investigação na escola (EIE)}

O EIE integra professores de diferentes níveis e modalidades com vistas a melhor compreensão dos processos educativos em desenvolvimento nas escolas e universidades, em diferentes sistemas de ensino. Os EIE, também foram fonte de inspiração para o Cirandar. Evento anual que ocorre no Rio Grande do Sul desde o ano de 2000, é desenvolvido pela Rede de Investigação na Escola (RIE) em parceria com a Universidade do Vale do Taquari (UNIVATES), a Pontifícia Universidade Católica do Rio Grande do Sul (PUCRS), a Universidade Regional do Noroeste do Estado do Rio Grande do Sul (UNIJUÍ), a Universidade Federal do Rio Grande (FURG), a Universidade Federal do Pampa (UNIPAMPA), a Universidade Federal de Santa Maria (UFSM) e a Universidade Federal Fronteira Sul (UFFS).

De acordo com Cacciamani e Galiazzi (2012), os Encontros sobre Investigação na Escola, no Rio Grande do Sul, têm origem nos eventos desenvolvidos pelo Grupo de Investigação na Escola da Faculdade de Ciências da Educação da Universidade de Sevilha (Espanha), nos anos 80, por iniciativa dos professores Rafael Porlán, Pedro Cañal e José 
Eduardo Garcia. A proposta do grupo desde o início foi proporcionar uma integração entre os professores de diferentes níveis de ensino e áreas do conhecimento, que organizou um evento anual intitulado Jornada de Estudos sobre Investigação na Escola com o objetivo de potencializar transformações nas ações docentes com participação de professores e coletivos renovadores.

O grupo buscou difundir a proposta organizando o I Seminario Iberoamericano de Diseño y Desarrollo Curricular en el alcance del proyect Inovación y Renovación Escolar - IRES em Huelva, na Espanha, em 1992. Este encontro proporcionou a consolidação das relações entre os professores espanhóis e latino-americanos. Este encontro se difundiu para a América Latina: Brasil, Argentina, Colômbia, México, Peru, Venezuela e Uruguai em coletivos de professores, que investigam suas práticas pedagógicas e proporcionam a inovação no espaço da escola.

Atualmente, coletivos desses países também se organizam em redes, pois constituem a Red Iberoamericana de Colectivos Escolares y Redes de Maestros/as que Hacen Investigación y Innovación desde la Escuela y Comunidad, que se reúne a cada três anos para discutir e socializar experiências. A proposta dos EIE no Brasil ocorreu a partir da participação de professores brasileiros no II Encontro Iberoamericano no México, em 1999. Este foi um fator importante no processo de organização dos encontros no Rio Grande do Sul, contando a participação de universidades com projetos interinstitucionais sobre a formação de professores de Ciências da Natureza e suas Tecnologias. Neste mesmo ano, em Alfafara (Espanha), ocorreram mudanças na proposta dos eventos sendo reunidos pela Red de Inovación y Renovación Escolar (Red Ires) fomentando a ampliação da formação da rede com o auxílio da Internet.

A experiência construída em rede - a Rede ACOMECIN das universidades gaúchas potencializou a formação em rede, que fomentou o EIE, originando a Rede de Investigação na Escola (RIE) no Rio Grande do Sul mais intensa e com professores de outros estados em menor número. O encontro foi organizado pelo grupo de professores do Centro Universitário Univates de 2000 a 2004 e a partir daí em diferentes universidades do Rio Grande do Sul.

No decorrer dos anos, em cada edição, professores pesquisadores da área de formação, provenientes de outras instituições, foram convidados a avaliar os encontros. As contribuições dos avaliadores nos encontros (re)significaram as propostas das edições 
seguintes. Uma delas sempre presente tem sido a necessária teorização da compreensão da prática docente.

A proposta do EIE se assemelha ao projeto analisado no item anterior pela importância que dá a escrita, no entanto, se diferencia dele porque sua aposta não está na exigência inicial de uma escrita com rigor acadêmico. Antes disso, é de acolhimento e encantamento de professores pelo processo de formação pela escrita, embora tenha a intenção de pela escrita, alcançar maior compreensão da prática docente.

O EIE se desenvolve anualmente pela escrita de relatos de experiência de sala de aula. No decorrer do processo esses relatos são lidos e dialogados entre pares, a distância, e durante o encontro presencial, ao final do processo formativo, são apresentados e discutidos entre os participantes, organizados em grupos em que todos os trabalhos são apresentados e discutidos pelo mesmo grupo. A intenção de melhoria do relato está colocada e no decorrer das edições esta interação tem-se aprimorado. Assim a escrita é artefato estruturante da formação acadêmico-profissional proposta.

Nesta parte do texto buscou-se salientar a contribuição dos EIE na organização do Cirandar a partir da escrita de relatos de sala de aula lidos entre pares, com produção de reescrita e encontro presencial de discussão de textos mais elaborados. No texto a seguir, dá-se ênfase ao projeto Cirandar e seu desenvolvimento no contexto mais recente.

\section{A ORGANIZAÇÃO DO CIRANDAR E ESTRUTURAÇÃO DAS RODAS}

O Cirandar traz as marcas de aprendizagens, anteriormente mencionadas, a necessidade de continuidade, a importância da permanência de professores experientes e a renovação dos participantes, sempre com novos integrantes em cada processo anual, do pertencimento ao lugar de atuação profissional, da complexidade que é fazer a formação acadêmico-profissional dada as condições dos contextos educativos pautados pela lógica da produtividade, fragmentação de tempos e espaços de formação, dentre outras coisas. Com isso, firma-se no compromisso político-ideológico, mas sem fins partidários, de que a formação de professores se dá de forma permanente e articulada nos diferentes níveis e modalidades de ensino, envolvendo também, estudantes de licenciaturas e pósgraduações. 
No Cirandar, propõe-se a escrita como ferramenta epistêmica. O ponto inicial da escrita marca um processo que tende a evoluir e que por meio dela o sujeito vai tomando consciência e produzindo novas aprendizagens (MARQUES, 2001; GALIAZZI, 2003). Os professores ao escreverem a respeito das experiências vividas nos espaços escolares, produzem significados sobre as mesmas ao compartilhá-la com outros professores. Esse exercício, favorece o (re)pensar, (re)significar e (re)construir as práticas educativas (CLANDININ; CONNELLY, 2011). Entende-se que as aprendizagens favorecidas são as que surgem no diálogo com esta diversidade de participantes com conhecimentos assimétricos, que possibilita enriquecimento de todos, na articulação dos saberes oriundos de diferentes níveis de complexidade.

Também se considera que o exercício de valorização do diferente e de aprendizagens mútuas a partir da diferença, como também o respeito às histórias e narrativas particulares de cada participante, possibilita crescimentos individuais e coletivos, isto é, inter e intrasubjetivo. Assim, cada participante vem a participar do Cirandar com a escrita de sua própria história, com modos de participação diferenciados, com os participantes tendo oportunidades de explorar suas vivências passadas, integrálas no presente e projetá-las para o futuro como reconstruções negociadas junto aos colegas.

O Cirandar iniciou em 2012, a $18^{\text {a }}$ Coordenadoria Regional de Educação convidou a FURG para desenvolver um processo de formação com os professores da rede de educação básica estadual em razão do desenvolvimento da reestruturação curricular do ensino médio, que instituiu o Ensino Médio Politécnico no Rio Grande do Sul. Durante três anos o Cirandar fez a formação tendo o foco nos Seminários Integrados, diferencial curricular nesta reestruturação.

Diferentemente dos anos anteriores, em 2015, o Cirandar estendeu a participação a todos os professores e licenciandos interessados, extrapolando a sua proposição inicial, pois com a mudança do governo do Estado do Rio Grande do Sul, os Seminários Integrados deixaram de vigorar. Boa parte das edições do Cirandar aconteciam com encontros presenciais no município do Rio Grande, sendo eles: o primeiro e o último encontro na FURG. As demais etapas eram mediadas de forma online, com as orientações em cartas. No ano de 2019 já havia uma expansão de polos do Cirandar, espalhados em 9 cidades do Rio Grande do Sul e ainda, um polo online, com uma sala constituída de 
participantes residentes em locais distantes dos polos presenciais - inclusive em outros estados brasileiros.

Essa expansão, se deu pelo desejo de continuidade dos participantes do Cirandar que foram atuar em outras instituições de ensino e deslocaram-se para outras cidades e estados. Em 2020, a expansão do projeto Cirandar consolidou-se em meio ao contexto pandêmico global que condicionou o desenvolvimento de trabalho remoto. A organização do Cirandar se viu em frente a um enorme desafio em sua nona edição: encontrar modos de desenvolver o Cirandar. Não havia dúvidas de que ele precisava acontecer, pois o projeto significa em sua base estrutural acolhimento.

Ao buscar modos de estruturação para a edição 2020 do cirandar, a comissão organizadora encontrou a parceria de mediadores para organizar as salas. O processo continuou mediado por cartas enviadas de forma online, porém, ao invés de contar com dois encontros, os mediadores tiveram autonomia para reunir sua sala mais vezes durante o processo e houve a organização de um encontro final para encontro e partilha de experiências estéticas de todas as salas. Ao todo, a edição contou com 14 salas online e parceria de 21 mediadores.

No projeto Cirandar desenvolvemos uma metodologia de trabalho que intensifica a interação entre professores por encontros sistemáticos entre os participantes, presenciais quando possível, e por ambientes virtuais. O foco está na escrita de relatos de experiências de sala de aula que o participante deseja discutir, apresentar, compreender e problematizar. Os relatos de experiências solicitados aos participantes são constituídos de narrativas vivenciadas pelos docentes durante o planejamento e desenvolvimento de atividades na sala de aula. $\mathrm{O}$ docente torna-se autor e investigador da sua própria prática pedagógica.

O processo formativo em Rodas possibilita que os professores, ao narrarem suas histórias de sala de aula, encontrem espaço para dialogar e refletir a respeito de suas práticas pedagógicas (WARSCHAUER, 2001; SOUZA, 2010). O sentido das Rodas é baseado nas contribuições de Souza (2010, p.152), segundo as quais, "o professor, ao narrar sua experiência na Roda, partilhando-a, a re-significa para si. Ao mesmo tempo, o outro se torna um interlocutor potencialmente aprendente nesse processo; o próprio significado de partilha implica esse pressuposto". Nas Rodas de Formação, os professores 
contam suas histórias e, ao contarem de si, contam também a respeito dos outros que os constituem e, ao contarem desses outros, contam de si (SOUZA, 2010).

As Rodas de Formação em Rede desenvolvidas no Cirandar têm como foco a compreensão do participante sobre seu papel político enquanto docente que assume a autoria de sua sala de aula. Para isso, é utilizado recursos como diálogo, escrita e leitura nas diferentes etapas de realização do projeto. Dependendo dos envolvidos, se desenvolvem com mais ou menos encontros entre os participantes. Conforme a edição de 2020, as etapas foram organizadas nas seguintes rodas:

- Roda de conversa virtuais: participantes experientes em edições anteriores foram contatados e convidados para coordenar salas com os participantes. Houve a promoção de encontros coordenados por esses mediadores convidados para dialogar sobre a experiência, modos de documentá-la, discutir fundamentos teóricos da Educação de modo a sustentar as atividades descritas nos relatos por cada um dos participantes; cada participante foi convidado a escrever cartas durante o processo formativo compondo o conjunto de três cartas.

- Roda de escrita: envio da primeira versão do relato de experiência composto pela união das três cartas escritas durante o processo (carta de apresentação, carta de indagações para fomentar o processo investigativo e carta com a narrativa das ações, decisão de estudo e aprofundamento teórico); leitura entre pares; envio de uma carta para o colega com contribuições no relato lido; reescrita do relato de experiência; reenvio da versão final do relato de experiência.

- Roda de leitura entre pares: leitura dos relatos dos participantes, nesta etapa cada participante lê o relato de experiência do colega. Com promoção de questionamentos do relato lido compõe-se uma carta com o parecer da leitura, de modo a construir a ideia de parceria com o colega, problematizar o individualismo e construir a ideia de parceria.

- Roda de publicação: publicização dos relatos de experiência e das cartas produzidas no site do cirandar; publicação dos relatos de experiências que foram finalizados, em forma de anais e/ou livros digitais e/ou livros; com os fundamentos da escrita narrativa na formação de professores com a escrita de textos de fundamentação de participantes e coordenadores da proposta. 
Deste processo de formação já foram publicados quatro livros com os relatos de professores, selecionados coletivamente por participantes do Cirandar (GALIAZZI, 2013; 2014; 2016; 2018) e um e-book (DORNELES, 2021). O ato de tornar público os relatos de experiências, constitui o momento em que os docentes narradores se convertem em autores de documentos pedagógicos e, através deles, seus saberes e experiências alcançam maior grau de objetividade e de estranhamento (SUÁREZ, 2011).

Assim, no Cirandar 2020, a Roda de Escrita se fez de modo um pouco diferente das outras edições, contando com auxílio da mediação dos coordenadores e das cartas que orientam cada etapa. Os participantes foram desafiados a escrever três cartas, com a proposta de juntas comporem a primeira versão do relato a ser submetida no site para a leitura entre pares e construção do relato de experiência final, partindo da contribuição expressa em uma carta com as impressões que o colega leitor escreveu sobre o relato lido. Abandona-se assim formatos fixos e afasta-se de moldes de escrita formatados que se aprende e se exercita na academia. Esta é marca presente nos relatos do projeto. E com isso, segue-se a Cirandar. Outras cirandas, outras Rodas de Formação sempre possíveis de se inventar.

\section{ALGUMAS CONSIDERAÇÕES FINAIS}

O projeto Cirandar acredita no exercício permanente da escrita como parte do processo de reflexão, de registro das experiências pedagógicas, de aprendizagem sobre ser professor, de problematização de teorias, crenças, valores. O desafio está principalmente na valorização da escrita sobre a prática docente e sobre os fundamentos teóricos que a sustentam, tendo-se aprendido nestes anos sobre a importância da escrita e da leitura como ferramenta formativa.

O processo de edição pedagógica dos livros já publicados com relatos de experiências do Cirandar atesta essa aposta. A experiência de publicação também se tornou espaço de formação dos professores envolvidos porque os relatos a serem publicados são escolhidos a partir de critérios e escolha coletiva.

O seu desenvolvimento em 2020, com especificidades diferentes, também é resultado de reflexões acerca desse e outros processos formativos. Afinal iniciamos a reflexão com o questionamento sobre qual formação é vista como pertinente. Nesse 
momento, não é intenção produzirmos um discurso definitivo e consensual, embora algumas iniciativas estejam sempre sendo testadas. Desse movimento reflexivo, surge a necessidade de proposição de projetos inventivos, organizados, mas ainda assim livres. A escrita como ferramenta epistêmica, contudo, é a grande aposta que unifica o processo formativo Cirandar.

\section{AGRADECIMENTOS}

Ao coletivo de professores que constituem o Cirandar. À Coordenação de Aperfeiçoamento de Pessoal de Nível Superior (CAPES).

\section{REFERÊNCIAS}

BRANDÃO, C. R. In: STRECK, D. R.; REDIN, E.; ZITKOSKI, J. J. (Orgs.). Dicionário Paulo Freire. 2. ed. Belo Horizonte: Autêntica Editora, 2010.

BRASIL. Documento Final. Conferência Nacional de Educação - CONAE, 2014. Disponível em: http://fne.mec.gov.br/images/DocumentoFinal29012015.pdf. Acesso em: 18 de maio de 2021.

CACCIAMANI, Jackson; GALIAZZI, Maria do Carmo. Os Encontros sobre Investigação na Escola: espaçotempo de formação acadêmico-profissional de professores de Química. Contexto \& Educação. Editora Unijuí. Ano 27, nº8, jul/dez. 2012.

CLANDININ, Jean; CONNELLY, Michael. Pesquisa Narrativa: experiência e história de pesquisa qualitativa. Tradução: Grupo de Pesquisa Narrativa e Educação de Professores ILEEL/UFU. Uberlândia: EDUFU, 2011.

DINIZ-PEREIRA, Júlio. A prática como componente curricular na formação de professores. Educação. Santa Maria, v. 36, n. 2, p. 203-218, maio/ago. 2011.

DORNELES, Aline Machado. Cirandar: rodas de investigação na escola. Rio Grande: editora da FURG, 2021.

GALIAZZI, Maria do Carmo. Educar pela pesquisa: ambiente de formação de professores de Ciências. Ijuí: Unijuí, 2003. 
GALIAZZI, Maria do Carmo; AUTH, Milton; MORAES, Roque.; MANCUSO, Ronaldo. (org.) Construção Curricular em Rede na Educação em Ciências: uma aposta de pesquisa na sala de aula. Ijuí: Unijuí, 2007.

GALIAZZI, Maria do Carmo; AUTH, Milton; MORAES, Roque.; MANCUSO, Ronaldo. (org.) Aprender em redes na Educação em Ciências. Ijuí: Unijuí, 2008.

GALIAZZI, Maria do Carmo. Cirandar: rodas de investigação desde a escola. São Leopoldo: Ed. OIKOS, 2013.

GALIAZZI, Maria do Carmo. Cirandar: rodas de investigação desde a escola. São Leopoldo: Ed. OIKOS, 2014.

GALIAZZI, Maria do Carmo. Cirandar: rodas de investigação desde a escola. Rio Grande: Editora da FURG, 2016.

GALIAZZI, Maria do Carmo. Cirandar: rodas de investigação desde a escola. Rio Grande: Editora da FURG, 2018.

LIMA, Cleiva Aguiar de. O diário em roda, roda em movimento: formar-se ao formar no PROEJA. Tese (Doutorado em Educação em Ciências) - PPGEC/ Universidade Federal do Rio Grande - FURG, Rio Grande, 2011.

MARQUES, Mario. O. Escrever é preciso: o princípio da pesquisa. Ijuí: Ed. Unijuí, 1997.

MORAES, Roque, GALIAZZI, Maria do Carmo. Rodas em Rede: formação de $\begin{array}{llll}\text { professores numa } & \text { perspectiva }\end{array}$ http://wp.ufpel.edu.br/colegiadoquimica/files/2011/08/TextoA.pdf. Acessado em 17 de julho de 2019.

SUÁREZ, Daniel. Indagación pedagógica del mundo escolar y formación docente. In: Revista del iice, № 30. Buenos Aires: Instituto de Ciencias de la Educación, Facultad de Filosofía y Letras, Universidad de Buenos Aires (pp. 17-32), 2011.

SOUZA, Moacir. Histórias de Professores de Química em Rodas de Formação em Rede: colcha de retalhos tecida em partilhas (d)e narrativas. Ijuí: Editora Unijuí, 2011.

WARSCHAUER, Cecília. Rodas em Rede: oportunidades formativas na escola e fora dela. Rio de Janeiro: Ed. Paz e Terra, 2001. 
DOI: http://dx.doi.org/10.5380/ef.v0i25

Recebido em: 25 de maio de 2021.

Aceito em: 26 de maio de 2021. 